Appl. Entomol. Zool. 32 (4): 609-615 (1997)

\title{
Seasonal Changes in Prevalence of Viral Disease and Parasitism by Parasitic Insects in a Larval Population of the Smaller Tea Tortrix, Adoxophyes sp. (Lepidoptera: Tortricidae) in a Tea Field
}

\author{
Madoka NAKAI, Masumi TAKEDA and Yasuhisa KUnIMI \\ Department of Applied Biological Science, Faculty of Agriculture, Tokyo University of \\ Agriculture and Technology, Fuchu, Tokyo 183, Japan
}

(Received 18 April 1997; Accepted 27 June 1997)

\begin{abstract}
The incidence of parasitoids and entomopathogens in a larval population of Adoxophyes sp. in a tea field in Tsukuba, Ibaraki Prefecture, was determined. Three species of Braconids, one species of Ichneumonid, and one species of Tachinid were identified in the collected larvae. Three entomopathogenic viruses, an entomopoxvirus (EPV), a nuclear polyhedrosis virus and a granulosis virus, were isolated from the dead larvae. Overall, $87.0 \%$ of Adoxophyes sp. larvae were killed by parasitoids and entomopathogens. Ascogaster reticulatus and EPV were the most common parasitoid and pathogen and were responsible for $37.7 \%$ and $23.1 \%$ of the deaths in the Adoxophyes sp. larvae, respectively. Percent parasitism by $A$. reticulatus was highest in the first generation and then decreased progressively toward the fourth generation. EPV prevalence was low in the first generation and increased through the generations. Of 333 host larvae dying from viral infection, $12.0 \%$ of host larvae contained dead parasitoid larvae. Some parasitoid larvae were able to emerge from virus-infected hosts, whereas these parasitoids died before or after pupation. The time to death of a parasitoid developing in virusinfected hosts appears to be closely related to the species of viruses.
\end{abstract}

Key words: Adoxophyes sp., natural enemy, Ascogaster reticulatus, entomopoxvirus, hostparasitoid-pathogen interaction

\section{INTRODUCTION}

The smaller tea tortrix, Adoxophyes sp., is a major pest of tea plants in Japan, and its control had depended on the use of synthetic pesticides. The development of resistance by this insect to the pesticides and the residue of pesticides on the harvested tea leaves have roused interest in finding ways to use biological agents for its control. YASUMATSU and WATANABE (1965), MomoI et al. (1975) and TAMAKI (1991) have reviewed the natural enemies of this insect, and have recorded 40 species of predators, parasitoids and pathogens in Japan. However, few quantitative data are available to evaluate the impact of these natural enemies upon Adoxophyes sp. In addition, competitive interaction between parasitoids and entomopathogens has been shown to occur during simultaneous parasitism of a host (BROOKS, 1993; HaRPER, 1986). Therefore, it is important to understand these interactions in the field in order to evaluate the role of each natural enemy. The purpose of this study was to quantify the presence of entomopathogens and parasitoids in larval populations of Adoxophyes sp. in a tea field during a one year period and to analyze the interactions between these two natural enemies. 


\section{MATERIALS AND METHODS}

Collection of insects. Parasitic natural enemies of Adoxophyes sp. were surveyed by collecting host larvae in a tea field in Tsukuba-shi, Ibaraki Prefecture in 1996. The tea field was planted with a Yabukita variety. No application of chemical insecticide was made throughout the survey. At least 110 larvae were randomly collected at each generation: April 6 (overwintering generation), June 15 (first generation), July 26 (second generation), September 6 and 16 (third generation) and October 31 (fourth generation). The collected larvae were brought into the laboratory and reared individually in $30 \mathrm{ml}$ plastic cups containing artificial diet (Insecta LF, Nihon Nosan Kogyo) under a $25^{\circ} \mathrm{C}, 16 \mathrm{~L} 8 \mathrm{D}$ photoperiod. Larval stadia were estimated by head-capsule width measurements at the time of collection.

Identification of pathogens. Dead larvae were dissected under the microscope to determine the presence of parasitoid larvae. The tissues of dead larvae were examined for polyhedra of a nuclear polyhedrosis virus (NPV) or spheroids of entomopoxvirus (EPV) in a wet mount by phase-contrast microscopy. Infection with the granulosis virus (GV) was determined by an enzyme-linked immunosorbent assay (ELISA) using mouse anti-occluded virion antiserum. A homogenate of dead larvae was used for the ELISA. The ELISA procedure was carried out using the method of KuBOtA and InOuE (1989).

\section{RESULTS AND DISCUSSION}

Of 862 Adoxophyes sp. larvae reared, $87 \%$ were killed by natural enemies. The percentage of larvae reaching adulthood differed between the generations: $18 \%$ for overwintering

Table 1. Percentage parasitism of Adoxophyes sp. larvae by each natural enemy

\begin{tabular}{lcc}
\hline \multicolumn{1}{c}{ Natural enemy } & $\begin{array}{c}\text { No. } \\
\text { collected }^{\mathrm{b}}\end{array}$ & $\begin{array}{c}\text { Percentage of } \\
\text { parasitism }\end{array}$ \\
\hline Ascogaster reticulatus & 325 & 37.7 \\
Apanteles adoxophyesi & 27 & 3.1 \\
Meteorus ictericus & 2 & 0.2 \\
Campoplex sp. & 1 & 0.1 \\
Unidentified parasitic wasps & 15 & 1.7 \\
Tachinidae gen. sp. & 3 & 0.3 \\
Mermithidae gen. sp. & 2 & 0.2 \\
Entomopoxvirus (EPV) & 199 & 23.1 \\
Nuclear polyhedrosis virus (NPV) & 31 & 3.6 \\
Granulosis virus (GV) & 19 & 2.2 \\
EPV + NPV & 55 & 6.4 \\
EPV + GV & 13 & 1.5 \\
NPV + GV & 13 & 1.5 \\
EPV + NPV + GV & 3 & 0.3 \\
Eynia radicans & 5 & 0.6 \\
Fusarium sp. & 1 & 0.1 \\
Unknown pathogens & 36 & 4.2 \\
\hline Total & 750 & 87.0 \\
\hline
\end{tabular}

a Adoxophyes sp. larvae were infected with two or more different kinds of viruses simultaneously.

${ }^{\mathrm{b}}$ A total of 862 Adoxophyes sp. larvae were reared. 

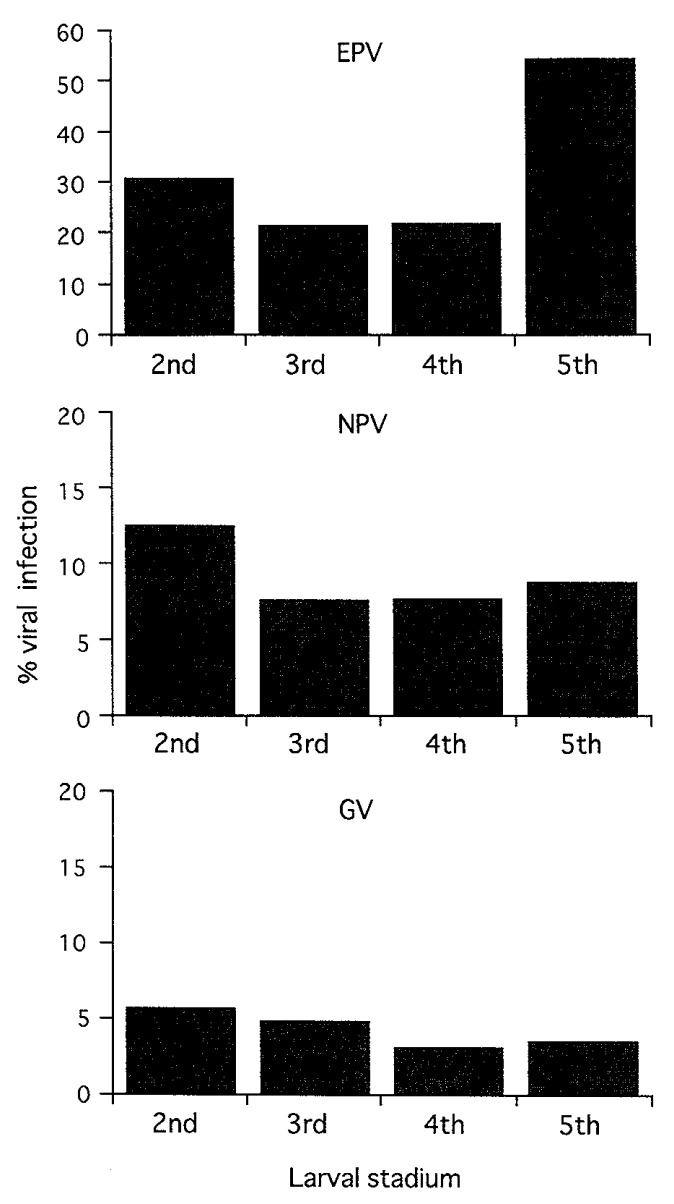

Fig. 1. Percentage of entomopoxvirus (EPV), nuclear polyhedrosis virus (NPV) and granulosis virus (GV) infection occurring in Adoxophyes sp. in different stadia collected in 1996 from a tea field in Ibaraki, Japan.

generation, $13 \%$ for the first generation, $10 \%$ for the second generation, $11 \%$ for the third generation and $15 \%$ for the fourth generation. The percentage parasitism of Adoxophyes sp. larvae by natural enemies is shown in Table 1. Three species of Braconids, one species of Ichneumonid, Tachinid and Nematodes were identified in the collected larvae. Three entomopathogenic viruses, EPV, NPV, GV, and two entomopathogenic fungi, Erynia radicans and Fusarium sp., were observed in the dead larvae.

The most dominant parasitic natural enemy was Ascogaster reticulatus (WATANABE, 1967), which caused $37.7 \%$ of all deaths in Adoxophyes sp. larvae. TAKAGI (1974) used a sticky suction trap and showed that the most common hymenopteran parasitoid of Adoxophyes sp. was Apanteles adoxophyesi, followed by $A$. reticulatus in a tea field in Shizuoka Prefecture. His results do not correspond to those from our study because the sticky suction trap could easily catch adult wasps, such as $A$. adoxophyesi, flying among the rows of tea bushes. In contrast to $A$. adoxophyesi, $A$. reticulatus adults spend most of the time walking on leaves rather than flying from leaf to leaf (SHimizu et al., 1991). As a result, $A$. reticulatus might not be caught as easily as $A$. adoxophyesi when using the sticky suction trap.

The most common entomopathogen identified in our study was EPV, which caused $23.1 \%$ of all deaths in the Adoxophyes sp. larvae. A high prevalence of EPV has been reported 
in a natural population of Adoxophyes sp., in Miyazaki Prefecture (IsHIKAwA et al., 1983). Although the presence of NPV in Adoxophyes orana (a species closely related to Adoxophyes sp.) has been reported in Europe (PONSEN and DE Jong, 1964), and this NPV has been shown to infect Adoxophyes sp. (SATO, 1981), the relationship between A. orana NPV and Adoxophyes sp. NPV has not yet been established. Of 333 larvae with viral infection, $25 \%$ were infected with two or more of the viruses simultaneously. Among those larvae, larvae infected with a mix of EPV and NPV were the most abundant (Table 1).

The second to fifth stadia were attacked by each of these three viruses (Fig. 1). The prevalence of these viruses was similar among the stadia. These results indicate that Adoxophyes sp. larvae might be infected with those viruses during early stadia.

Seasonal changes in the occurrence of parasitism in Adoxophyes sp. by its primary natural enemies is shown in Fig. 2. EPV prevalence declined from the overwintering to the first generation. The reason for this is unknown. However, the buds of the tea leaves were harvested just before the infestation of the first generation occurred. This suggests that, as the virus population on the tea leaves decreases, the vertical transmission rate of EPV may also decline, as was seen in the change between the overwintering and the first generation. EPV prevalence increased after the first generation. Other authors have also reported that

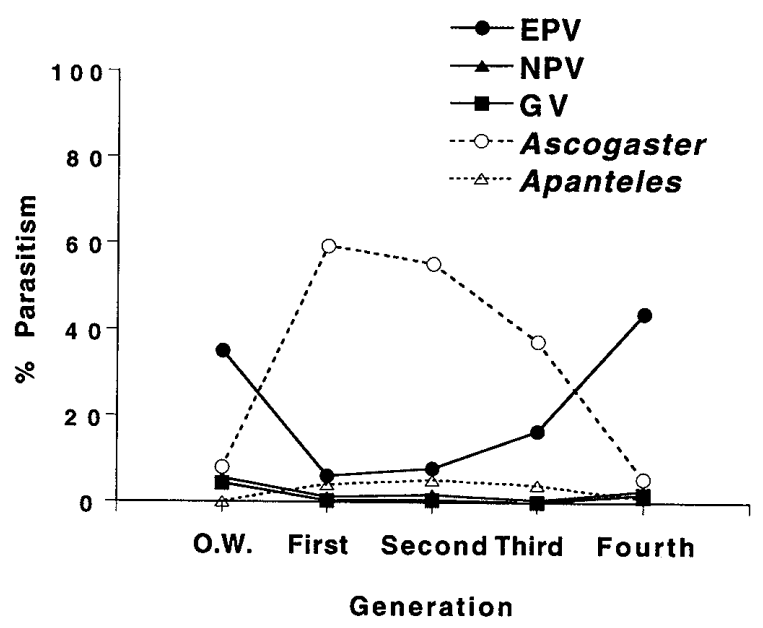

Fig. 2. Seasonal fluctuation of percentage parasitism by natural enemies of Adoxophyes sp. larvae collected in 1996 from a tea field in Ibaraki, Japan. Entomopoxvirus (EPV), nuclear polyhedrosis virus (NPV), granulosis virus (GV), Ascogaster reticulatus (Ascogaster), and Apanteles adoxophyesi (Apanteles) were the primary natural enemies.

Table 2. Percentages of virus-killed Adoxophyes sp. larvae containing parasitoid larvae

\begin{tabular}{lcc}
\hline Generation & $\begin{array}{c}\text { No. of virus-killed } \\
\text { hosts }\end{array}$ & $\begin{array}{c}\text { Percentage containing } \\
\text { parasitoid larvae }\end{array}$ \\
\hline Overwintering & 111 & 7.2 \\
First & 42 & 26.2 \\
Second & 38 & 23.7 \\
Third & 68 & 8.8 \\
Fourth & 74 & 8.1 \\
\hline Total & 333 & 12.0 \\
\hline
\end{tabular}


Table 3. Relationship between the conditions of parasitoid death and the viral species infecting Adoxophyes sp. larvae

\begin{tabular}{lcccc}
\hline & & \multicolumn{3}{c}{ Percentage of parasitoid larvae showing } \\
\cline { 3 - 5 } Virus species infecting hosts & No. observed & Premature death & $\begin{array}{c}\text { Death occurred } \\
\text { after emergence }\end{array}$ & $\begin{array}{c}\text { Death occurred } \\
\text { after pupation }\end{array}$ \\
\hline Entomopoxvirus & 35 & 60.0 & 31.4 & 8.6 \\
Nuclear polyhedrosis virus & 12 & 33.3 & 66.7 & 0 \\
Granulosis virus $_{\text {Viruses }}{ }^{\text {a }}$ & 8 & 25.0 & 75.0 & 0 \\
\hline Total & 21 & 61.9 & 33.3 & 4.8 \\
\hline
\end{tabular}

${ }^{a}$ Host larvae were infected with two or more different kinds of viruses.

the prevalence of viral diseases appears to increase through the generations of the insects (EHLER, 1977; Hukuhara, 1975), but the reasons for this have not been cited.

The rates of parasitism in Adoxophyes sp. larvae by $A$. reticulatus were lower in the generations showing a high EPV prevalence (the overwintering and fourth generations) than in those with a low EPV prevalence (the first and second generations). Regression analysis revealed a significant linear relationship between parasitism rates by $A$. reticulatus and EPV prevalence $(r=-0.99, p<0.01)$, where data were arcsin root transformed before analysis. This may indicate that $A$. reticulatus and EPV were in competition. KoDOMARI (1987) reported that levels of parasitism in Adoxophyes sp. larvae by parasitic insects declined in a tea field where GV was applied to control Adoxophyes sp. There are some other examples where the levels of parasitism were reduced when viruses had been applied to the fields (SHiga et al., 1973; FALCON, 1973).

The percentage of virus-infected Adoxophyes sp. larvae containing parasitoid larvae is shown in Table 2. The highest value was obtained in the first generation $(26.2 \%)$, and these parasitoid larvae could not complete development in virus-infected hosts, resulting in premature death. Although some parasitoid larvae could emerge from the virus-infected hosts, these parasitoid larvae were killed before or after pupation. The relationship between the conditions of parasitoid death and the viral species infecting the host larvae is shown in Table 3. The relationship between the time to parasitoid death (premature death, death after emergence and death after pupation) and viral species infecting the host larvae (EPV, NPV and GV) was analyzed using a $\chi^{2}$ test. Most of the parasitoid larvae developing in EPV-infected hosts died before they emerged from the host larvae, whereas those developing in GV- or NPV-infected hosts died after emergence from their hosts (Table 3). The time to parasitoid death was significantly different among host larvae infected with different viral species $\left(\chi^{2}=9.65, \mathrm{df}=4, p<0.05\right)$. In the laboratory experiment, more than $80 \%$ of $A$. reticulatus failed to emerge from the host when neonate parasitized Adoxophyes sp. larvae were inoculated with EPV (NAKAI et al., 1997). On the other hand, most of the parasitoid larvae developing in GV- or NPV-infected hosts died after emergence from their hosts (Table 3). When neonate parasitized Adoxophyes sp. larvae were inoculated with GV, more than $90 \%$ of $A$. reticulatus emerged from the hosts and then died before pupation (NAKAI and KUNIMI, 1997). It is clear that the results from this field study correspond to the results from the laboratory studies. In this study, we found that both NPV and GV from Adoxophyes sp. killed their hosts slowly (NAKaI et al., unpubl.). Therefore, the impact of NPV-infection of the hosts on parasitoid larvae may be similar to that of GV. Our results indicate that the 
survival of parasitoids can be adversely affected when rates of viral infection in the hosts are high.

\section{ACKNOWLEDGEMENTS}

We thank Dr. K. MaEtoh, Forestry and Forest Products Research Institute and Dr. K. KonishI, National Institute of Agro-Environmental Science, for the determination of Braconidae and Ichneumonidae, respectively. We also thank an anonymous referee for critical reading and valuable suggestions.

\section{REFERENCES}

Brooks, W.M. (1993) Host-parasitoid-pathogen interactions. In Parasites and Pathogens of Insects, Vol. 2 (N.E. Beckage, S.N. Thompson and B.A. Federici, eds.). Academic Press, New York, pp. 231-272.

EHLER, L.E. (1977) Natural enemies of cabbage looper on cotton in the San Joaquin Valley. Hilgardia 45: $72-106$.

FALCON, L.A. (1973) Biological factors that affect the success of microbial insecticides: development of integrated control. In Regulation of Insect Populations by Microorganisms (L.A. BullA, Jr., ed.). The New York Academy of Sciences, New York, pp. 173-186.

HARPER, J.D. (1986) Interactions between baculoviruses and other entomopathogens, chemical pesticides, and parasitoids. In The Biology of Baculoviruses, Vol. 2 (R.R. Granados and B.A. Federici, eds.). CRC Press, Boca Raton, FL, pp. 133-156.

Hunuhara, T. (1975) Distribution of viruses of the fall webworm in soil. In Development Microbiology Ecology (T. Hasegawa, ed.). Science Council of Japan, Tokyo, pp. 658-665.

Ishikawa, I., A. Shimamura and H. Watanabe (1983) A new entomopoxvirus disease of the smaller tea tortrix, Adoxophyes sp. (Lepidoptera: Tortricidae). Jpn. J. Appl. Entomol. Zool. 27: 300-303 (in Japanese with English summary).

Kodomari, S. (1987) Control of leafrollers with granulosis viruses in tea field. 1. Effectiveness of application of GV mixture of oriental tea tortrix and smaller tea tortrix. Bull. Shizuoka Tea Exp. Stn. 13: 39-48 (in Japanese with English summary).

Kubota, T. and H. Inoue (1989) Nuclear polyhedrosis virus infection in a highly susceptible cell line of Bombyx mori (Lepidoptera: Bombycidae) detected by enzyme-linked immunosorbent assay. Appl. Entomol. Zool. 24: 480-482.

Momol, S., H. Sugawara and K. Honma (1975) Ichneumonid and Braconid parasites of Lepidopterous leafrollers of economic importance in horticulture and tea-culture (Hymenoptera). In Approaches to Biological Control (K. Yasumatsu and H. Mori, eds.). University of Tokyo Press, Tokyo, pp. 47-60.

NAKaI, M. and Y. Kunimi (1997) Granulosis virus infection of the smaller tea tortrix (Lepidoptera: Tortricidae): Effect on the development of the endoparasitoid, Ascogaster reticulatus (Hymenoptera: Braconidae). Biol. Control 8: 74-80.

NaKal, M., T. SAKaI and Y. Kunimi (1997) Effect of entomopoxvirus infection of the smaller tea tortrix, Adoxophyes sp. on the development of the endoparasitoid, Ascogaster reticulatus. Entomol. Exp. Appl. 84: 27-32.

Ponsen, M.B. and D.J. De Jong (1964) On a nuclear and cytoplasmic polyhedrosis of Adoxophyes reticulana HB. Entomophage 9: 253-255.

SAто, T. (1981) Mass rearing method of a leafroller, Adoxophyes sp. for propagation of its granulosis virus. Shokubutsu boeki 35: 233-237 (in Japanese).

Shiga, M., H. Yamada, N. Oho, H. Nakazawa and Y. Ito (1973) A granulosis virus, possible biological agent for control of Adoxophyes orana (Lepidoptera: Tortricidae) in apple orchards. J. Invertebr. Pathol. 21: 149157.

Shimizu, K., Y. Kainoh and S. TATsuki (1991) Diurnal searching pattern of Ascogaster reticulatus Watanabe (Hymenoptera: Braconidae) in tea field. Jpn. J. Appl. Entomol. Zool. 35: 258-260 (in Japanese with English summary).

TAKAGI, K. (1974) Monitoring of hymenopterous parasite in tea field. Bull. Natl. Res. Inst. Tea 10: 91-131 (in Japanese with English summary). 
Tamaki, Y. (1991) Tortricids in tea. In Tortricid Pests Their Biology, Natural Enemies and Control (L.P.S. Van der Geest and H.H. Evenhuis, eds.). Elsevier, Amsterdam, pp. 541-551.

Watanabe, C. (1967) Description of a new species of the genus Ascogaster Wesmael and notes on synonymy of Apanteles species (Hymenoptera, Braconidae). Insecta Mastumurana 29: 41-44.

Yasumatsu, K. and C. Watanabe (1965) A Tentative Catalog of Insect Natural Enemies of Injurious Insects in Japan. Part 2. Host Parasite-Predator Catalog. Entomological Laboratory, Faculty of Agriculture, Kyushu University, Fukuoka, $116 \mathrm{pp}$. 